\title{
Dextrinized Maize Starch-Maize Starch Combination as Exclusive Fillers in Tablet Manufacture
}

\author{
S. SABALINGAM*, G. H. G. U. APSARA DHARMAWANSHA, M. D. J. WIJAYABANDARA, M. A. SIRIWARDHENE AND \\ W. PATHIRANA ${ }^{1}$
}

Department of Pharmacy and Pharmaceutical Sciences, Faculty of Allied Health Sciences, University of Sri Jayewardenepura, Gangodawila, Nugegoda, ${ }^{1}$ Department of Pharmacology and Pharmacy, Faculty of Medicine, University of Colombo, Kynsey Road, Colombo 08, Sri Lanka

\section{Sabalingam et al.: Dextrinized Starch-starch as Exclusive Tablet Fillers}

Traditional tablet filler combinations, lactose-maize starch were replaced with a new dextrinized maize starch-maize starch filler combination. Dextrinization process under controlled conditions was targeted for this purpose and specifications were determined for the dextrinized product. Granules were prepared by wet granulation method using the new filler combination. Placebo tablets T1 were first prepared with lactose-maize starch filler combination as a model. Based on the properties of resulting tablets, lactose was replaced with dextrinized maize starch, introduced a different binder and the active ingredient furosemide anticipating a tablet of acceptable quality. The flow properties of dextrinized maize starch had improved over maize starch with an angle of repose of $40^{\circ}$. Hausner ratio and Carr's index of dextrinized maize starch and lactose were found to be $1.34,1.54$, and $25.45,35.24 \%$, respectively favourable to the former. The placebo tablets (T2) prepared with the new filler combination using $12.0 \% \mathrm{w} / \mathrm{w}$ maize starch binder resulted in unacceptable hardness and friability. However, furosemide tablets (T3) prepared with the new filler combination and the binder solution of low substituted hydroxypropyl cellulose $3.2 \%$ w/w showed excellent physical properties. The study shows that dextrinized maize starch and maize starch filler combination without lactose could be employed successfully in tablet manufacture. 


\section{Key words: Dextrinized maize starch, maize starch, lactose, spongiform encephalopathy, Maillard-reaction}

Pharmaceutical industry is one of the crucial industries in the world, which requires uninterrupted production and distribution. Pharmaceutical fillers provide sufficient bulk to the tablets for convenient handling, making it feasible to manufacture and therefore convenient for the consumer to consume them. Lactose constitutes the bulkiest of many of the tablet fillers dominating this position for about a century, the authors were of the opinion that there should be a suitable substitute in its place. Maize starch (MS) is the second commonest filler. These two go hand-in-hand in most tablet formulations and the industry accepts this without questioning. Discovery and development of a novel excipient is a costly process, though it should be carried out to support and maintain the consistency of the manufacturing process ${ }^{[1]}$. The main purpose of this study was to manufacture tablets with exclusive fillers consisting only starches. This can be achieved by using dextrinized maize starch (DMS)-MS filler combination.

Lactose is the most commonly used filler in tablets ${ }^{[2]}$. Sucrose, glucose, mannitol, calcium phosphate, calcium carbonate and cellulose derivatives have also been used as fillers in tablet manufacturing. An ideal filler should be biologically inert, non-hygroscopic, soluble, relatively cheap, preferably tasteless or pleasant-tasting, compatible with active pharmaceutical ingredients (API) and other excipients as well as able to carry high amount of API. Only few substances comply with the above mentioned characteristics ${ }^{[3]}$.

Lactose is a disaccharide, a byproduct of dairy industry ${ }^{[4]}$. Lactose will get metabolized into glucose and galactose by intestinal lactase enzyme. Patients who have lactase deficiency are known as lactose intolerant patients. These patients lack partial or full metabolism of lactose. Undigested lactose cause abdominal discomfort, bloating, flatulence, diarrhoea, nausea and abdominal cramps $^{[5]}$. A study from UK reported that patients who were diagnosed with GI symptoms face increased discomfort due to the presence of lactose in medicines ${ }^{[6]}$. After production, lactose contains traces of their bovine source. This exhibit theoretical risk of transmissible spongiform encephalopathy ${ }^{[7]}$.

Lactose is also a reducing sugar which reacts with primary and secondary amines and creates brown pigmented byproduct and leads to degradation of API carrying amino groups ${ }^{[8]}$. This reaction is called as Maillard-reaction which has been reported for antidepressant fluoxetine (a secondary amine) when formulated with lactose. Formulations prepared with starch diluent did not yield such degradation products ${ }^{[9]}$. Further, lactose contains several impurities, which can cause incompatibilities with API. The impurities can be various aldehydes like formaldehyde, acetaldehyde and furfuraldehyde, lactose phosphate, organic acids, nitrites and nitrates. Presence of these impurities in dosage forms lead to shelf life issues ${ }^{[10]}$.

The problems of lactose encouraged researchers to find an alternative filler. Microcrystalline cellulose, mannitol, sorbitol and calcium hydrogen phosphate dihydrate are some pharmaceutical excipients used to prepare tablets without lactose. Some worldwide manufacturing companies produce tablets without lactose. Tablets prepared with pre-gelatinized MS (Starch 1500) in a direct compression formula have more benefits than lactose-based tablets ${ }^{[11]}$.

MS is a high molecular weight polymeric carbohydrate consisting of a large number of glucose monomers linked by glycosidic bond. It consists of two types of glucose polymers, the linear amylose $(28 \%)$ and highly branched amylopectin $(72 \%)^{[12]}$. Short chains of amylopectin are known to form double-helices, which crystallize and provide the semi crystalline (containing both crystalline and amorphous parts) nature to the starch granules ${ }^{[13]}$. Because of this semi-crystalline nature and elasticity, MS cannot be directly used as a filler to replace lactose. Tablets formulated solely with MS perform poorly in hardness and friability. In a previous study tablets prepared with starch showed a height reduction or 'recompression' in the early stage of ejection. Later, a height expansion or 'relaxation' was observed as they moved further towards the die exit, which clearly shows the elastic nature of the $\operatorname{starch}^{[14]}$. Lactose is a crystalline solid behaving within

This is an open access article distributed under the terms of the Creative Commons Attribution-NonCommercial-ShareAlike 3.0 License, which allows others to remix, tweak, and build upon the work non-commercially, as long as the author is credited and the new creations are licensed under the identical terms

Accepted 05 July 2019

Revised 25 February 2019

Received 31 December 2018

Indian J Pharm Sci 2019;81(5):960-966 
defined physical properties during tablet manufacture. It can be compressed close to its true density and due to the hard nature of lactose it can be consolidated well ${ }^{[15]}$. Therefore, it is necessary to convert MS closer to the better defined properties of crystalline lactose for it to perform well as a substitute for lactose.

The crispy fine pieces that fall off the crust while slicing bread hinted about the possibility of dextrinization of MS for the purpose. The characteristics of these fragile pieces are distinctly different from the soft elastic centre of the loaf of bread possibly due to roasting of exposed surface while baking. Therefore, the best way was to subject MS into a process of controlled roasting leading to the dextrinization of MS by heat treatment. Dextrin prepared by heat treatment is known as pyrodextrin ${ }^{[16]}$. The dextrinization process involves hydrolysis, transglycosidation, repolymerization, and oxidation. New glycosidic linkages formed during dextrinization will increase the solubility and reduce the viscosity of solutions ${ }^{[17]}$. The heating process, decreases the molecular size and increases the degree of branching and glucosidic linkages. Thereby, turning the product into a more rigid form ${ }^{[18]}$. The broader aim of the study was to establish a much wider use for the DMS as a tablet filler than merely to overcome sensitivity reactions to lactose. The dextrinization under this project basically aimed at generating rigidized MS particles to replace lactose rather than preparing dextrin of official compendia standards.

Pharmacopoeial grade MS, lactose and purified talc were procured from Astron Pvt. Ltd, Galle Road, Ratmalana, Sri Lanka. Furosemide, colloidal silicon dioxide, magnesium stearate and hydroxypropyl cellulose-L (HPC-L) type was obtained from State Pharmaceuticals Manufacturing Cooperation, Sir John Kotalawala Mawatha, Ratmalana, Sri Lanka. All the chemicals used in the analysis were of analytical grade. Granules were prepared in the laboratory of the B. Pharm Degree Program, Faculty of Medical Sciences, University of Sri Jayewardenepura. Hot air drying oven Memmert UF160 (laboratory modelEF2W, Germany) was used for the dextrinization of starch. IR moisture meter (model-SR-610A, China) was used to determine the moisture content of the granules. Tableting was carried out in Astron Pvt Ltd, using KMPC-10 (Kambert Machinery, Ahmedabad, India) 10 station tableting machine.

DMS at temperatures between $125^{\circ}-213^{\circ}$ would produce continuous hydrolytic degradation of starch.
The rate of degradation increases with increasing temperature $^{[19]}$. Dextrinization process barely starts at temperature between $120^{\circ}$ and $150^{\circ}$, but the colour changes are not distinctly observable. The first evident change occurs at temperature between $170^{\circ}-190^{\circ}$, and the changes are rapid at $230^{\circ}[20]$. Temperature selection has to be considered with the quantity to be dextrinized. In the present study appropriate time for the dextrinization was identified by a systematic process using $100 \mathrm{~g}$ of MS without the use of moisture or acid. The sample was dextrinized at $180^{\circ}$ using the hot air oven in order to identify the appropriate time for the dextrinization. Every $0.5 \mathrm{~h}$ the MS layer was turned and spread evenly. Approximately $1 \mathrm{~g}$ samples were taken at $30 \mathrm{~min}$ intervals up to $4 \mathrm{~h}$ and identification test for dextrinization was performed according to the monograph dextrin BP. Same identification tests were carried out for untreated MS as well and dextrinization period was identified as $2.5 \mathrm{~h}$ at $180^{\circ}$. The DMS was allowed to cool and packed in appropriately labelled airtight container.

Tests such as microscopic identification, chemical identification, solubility, loss on drying, $\mathrm{pH}$ and sulphated ash content for MS and DMS were carried out according to British Pharmacopeia ${ }^{[21]}$. Angle of repose, bulk and tapped densities and hygroscopicity were determined for MS, DMS and lactose. Hausner's ratios and Carr's index of MS, DMS and lactose were calculated according to British Pharmacopeia ${ }^{[21]}$. To determine the moisture absorption capacity 3 samples of $5.00 \mathrm{~g}$ of DMS was spread in tared watch glass and dried in a hot air oven at $65^{\circ}$ until constant weight $(2 \mathrm{~h})$. DMS was removed from the hot air oven and kept in the constant humidity chamber $75 \% \mathrm{RH}$ at room temperature $29^{\circ}$ until weight gain was constant $(3 \mathrm{~h})$. The final weight of the DMS was determined and percentages of weight loss and weight gain were calculated. Same procedure was followed for the MS. Particle size distribution for the two starches was determined by sieve analysis using 300, 150 and 75 micron sieves. Retained powder was collected and the size distribution of powder in each sieve was determined.

Initially, placebo tablets were prepared using lactoseMS (T1) and DMS-MS (T2) as fillers using starch binder and their properties were compared. On the basis of these results, the study was proceeded with the preparation of furosemide tablets BP $40 \mathrm{mg}$ using low substituted HPC-L binder (T3 and T4). The batch size was $250 \mathrm{~g}$ with a target tablet weight of $200 \mathrm{mg}$. 
Four different batches of granules were prepared using varying concentration of MS and HPC-L binders by wet granulation method (Table 1).

In the trial T1, given quantities of lactose and MS were passed through 850 micrometer sieve and mixed. Purified water $30 \mathrm{ml}$ was warmed to $60^{\circ}$ and another $55 \mathrm{ml}$ of purified water was boiled. MS $15.00 \mathrm{~g}$ was transferred into purified water at $60^{\circ}$ while stirring vigorously. The resulting starch suspension was transferred into $55 \mathrm{ml}$ of boiling water while stirring vigorously. In trial T2, DMS and MS were similarly mixed and the binder was similarly prepared to that of T1 using double the quantities. The stirring was continued and allowed to cool. The resulting starch binders were added to the appropriate filler powder mixtures and kneading continued until all traces of free powder disappeared forming the wet dough. The dough was pressed through $2 \mathrm{~mm}$ sieve to form wet granules and dried in a preheated oven at $55^{\circ}$. The trays were removed and turned the granules to expose wet areas after $2 \mathrm{~h}$. Drying was continued until the moisture content reached 1-2\%. The moisture content of granules was determined using a $5.00 \mathrm{~g}$ sample in an IR moisture meter. The dried granules were reduced to more or less even size and were passed through an 850 micrometer sieve. In trials T3 and T4 fillers DMS, MS and furosemide were similarly mixed, granulated with HPC-L binders of appropriate strengths, dried and milled to size (Table 1).

Dried granules were mixed with purified talc $12.5 \mathrm{~g}$ for $1 \mathrm{~min}$. Colloidal silicon dioxide $0.43 \mathrm{~g}$ and magnesium stearate $1.25 \mathrm{~g}$ were added and mixed for $20-30 \mathrm{~s}$. The $\%$ fineness was checked by passing $10 \mathrm{~g}$ of granules through 80 micrometer mesh. Likewise, the $\%$ fineness was calculated and the blend was compressed into tablets. Tablets were appropriately labelled and stored in airtight containers protected from light.

The following tests were carried out on the tablets according to British Pharmacopeia ${ }^{[21]}$. The product consists of white, circular, biconvex, $8 \mathrm{~mm}$ diameter tablets with a break line on one side, each weighing $200 \mathrm{mg}$. Thickness and diameter was determined using ten randomly selected tablets. The mean tablet weight was determined by weighing twenty randomly selected tablets on a precision balance (Model-AR1530, Ohaus Corporation, USA) and the average determined.

Disintegration test was carried out in distilled water with the disintegration tester Erweka ZT22X (modelED2L, Mumbai, India) and friability of tablets was determined with a friability test apparatus (ModelEF2W, Mumbai, India) as per British Pharmacopoeia. Hardness was determined for ten randomly selected tablets, using TBH 225 hardness tester (Model-EHO1, Mumbai, India).

In this study MS and dextrin identification tests were done according to the British Pharmacopeia ${ }^{[21]}$. MS showed dark blue colour with iodine solution. After $2.5 \mathrm{~h}$ of dextrinization process DMS showed light purple colour with iodine solution. The colour changes observed in identification tests between MS and DMS indicates the structural differences after successful dextrinization process.

Comparative studies on physical properties were carried out on the 3 fillers involved in the study as these are indicative of the suitability as filler. All physical tests for DMS complied with the applicable British Pharmacopeia specifications. Dextrinized product has roughly $20 \%$ less moisture content than untreated MS (Table 2). This shows that the heating process during

TABLE 1: FORMULAE FOR EXPERIMENTAL BATCHES OF TABLETS

\begin{tabular}{|c|c|c|c|c|}
\hline \multirow[b]{2}{*}{ Ingredient } & \multicolumn{4}{|c|}{ Formulae for trial tablets (g) } \\
\hline & $\begin{array}{c}\mathrm{T} 1 \\
\text { (MS+lactose) }\end{array}$ & $\begin{array}{c}\text { T2 } \\
\text { (MS+DMS) }\end{array}$ & $\begin{array}{c}\mathrm{T} 3 \\
(\mathrm{MS}+\mathrm{DMS}+\mathrm{FR})\end{array}$ & T4 (MS+DMS+FR) \\
\hline Furosemide & - & - & 50.00 & 50.00 \\
\hline Lactose, filler & 170.4 & - & - & - \\
\hline DMS, filler & - & 159.24 & 137.61 & 134.63 \\
\hline MS, filler & 57.50 & 53.66 & 47.29 & 46.27 \\
\hline MS, binder (strength) & $15.00(6.0 \% \mathrm{w} / \mathrm{w})$ & $30.00(12.0 \% \mathrm{w} / \mathrm{w})$ & - & \\
\hline HPC-L, binder (strength) & - & - & $8.00(3.2 \% w / w)$ & $12.00(4.8 \% \mathrm{w} / \mathrm{w})$ \\
\hline Purified talc & 12.50 & 12.50 & 12.50 & 12.50 \\
\hline Magnesium stearate & 1.25 & 1.25 & 1.25 & 1.25 \\
\hline Colloidal silicon dioxide & 0.43 & 0.43 & 0.43 & 0.43 \\
\hline DI water $(\mathrm{ml})$ & 85.0 & 170.0 & 80.0 & 80.0 \\
\hline Total end weight, (dry basis) & 250.00 & 250.00 & 250.00 & 250.00 \\
\hline
\end{tabular}

MS is maize starch, DMS is dextrinized maize starch, FR is furosemide, HPC-L is low substituted hydroxypropyl cellulose 
dextrinization has altered the starch grain structure and its capacity to absorb moisture. Among the 3 fillers DMS has the minimum angle of repose indicative of a fairly good flow property. Examination of density parameters show that among the three fillers, DMS has the most favourable Hausner's Ratio and Carr's Index in relation to flow property contributing towards uniform tablet weight.

Data showed that DMS is comparatively more stable to hygroscopic changes than MS (Table 3). Solubility criteria of MS and DMS in cold and hot waters showed a clear difference between the 2 starches. Only lactose is freely soluble in water and all fillers were insoluble in ethanol. Dextrinization has resulted in $100 \%$ finer particle size of less than $75 \mu \mathrm{m}$.

Results of physical tests carried out for the 4 tablet formulations are given in Table 4. It is evident that the weight variation range based on standard deviation is reduced to about $50 \%$ in trials $\mathrm{T} 2, \mathrm{~T} 3$ and $\mathrm{T} 4$ in which DMS was used when compared to $\mathrm{T} 1$ in which lactose was used. Given the low friability and high disintegration time in formula $\mathrm{T} 3$, it is possible to use a lower concentration HPC-L binder from the present $3.2 \% \mathrm{w} / \mathrm{w}$ solution.

All dosage forms consist of a drug substance together with varying number excipients. The main objective was to identify an alternative excipient to lactose as a filler in tablet manufacture despite its wide acceptability. DMS produced under controlled conditions was tested as an alternative new filler in order to understand its performance in physical quality of tablets. The DMS is characterized by the test parameters set out in Tables 2 and 3. It may be possible that DMSs with marginally different specifications to this product may still be able to yield good quality tablets. However, the product must assume crystalline nature from the former amorphous

TABLE 2: PHYSICAL TEST RESULTS OF FILLERS

\begin{tabular}{lccccccccc}
\hline \multirow{2}{*}{ Filler } & \multicolumn{10}{c}{$\begin{array}{c}\text { Loss on } \\
\text { drying (\%) }\end{array}$} & $\mathrm{pH}$ & $\begin{array}{c}\text { Sulfated } \\
\text { ash (\%) }\end{array}$ & $\begin{array}{c}\text { Angle of } \\
\text { repose }\end{array}$ & $\begin{array}{c}\text { Flow } \\
\text { property }\end{array}$ & $\begin{array}{c}\text { Tapped } \\
\text { density }\end{array}$ & $\begin{array}{c}\text { Bulk } \\
\text { density }\end{array}$ & $\begin{array}{c}\text { Hausner's } \\
\text { ratio }\end{array}$ & $\begin{array}{c}\text { Carr's } \\
\text { index (\%) }\end{array}$ \\
\hline MS & $9.33 \pm 1.15$ & $6.47 \pm 0.3$ & $0.50 \pm 0.03$ & $48.7^{\circ}$ & Poor & 0.66 & 0.48 & 1.36 & 26.63 \\
DMS & $7.33 \pm 0.58$ & $6.71 \pm 0.2$ & $0.45 \pm 0.02$ & $40^{\circ}$ & Fair & 0.68 & 0.51 & 1.34 & 25.45 \\
Lactose & - & - & - & $50.41^{\circ}$ & Poor & 0.76 & 0.46 & 1.54 & 35.24 \\
\hline
\end{tabular}

MS is maize starch, DMS is dextrinized maize starch

TABLE 3: MOISTURE CONTENT, HYGROSCOPICITY, SOLUBILITY AND PARTICLE SIZE DISTRIBUTION OF FILLERS

\begin{tabular}{|c|c|c|c|c|c|c|c|c|}
\hline \multirow{2}{*}{ Filler } & \multirow{2}{*}{$\begin{array}{c}\text { Moisture content } \\
\text { Wt. loss } \\
\left(65^{\circ}, 2 \mathrm{~h}\right)\end{array}$} & \multirow{2}{*}{$\begin{array}{c}\text { Hygroscopicity } \\
\text { Wt. gain, } \\
\left(29^{\circ}, 3 \mathrm{~h}, 75 \% \mathrm{RH}\right)\end{array}$} & \multicolumn{3}{|c|}{ Solubility } & \multicolumn{3}{|c|}{$\begin{array}{c}\text { Size distribution \% } \\
\text { Sieve size in } \mu \mathrm{m}\end{array}$} \\
\hline & & & $\begin{array}{c}\text { Water } \\
28^{\circ}\end{array}$ & $\begin{array}{l}\text { Water } \\
100^{\circ}\end{array}$ & $\begin{array}{l}\text { Ethanol } \\
95 \%\end{array}$ & $300-150$ & $150-75$ & $<75$ \\
\hline MS & $14.02 \%$ & $11.35 \%$ & Insoluble & $\begin{array}{l}\text { Insoluble } \\
\text { forming hazy } \\
\text { mucilage }\end{array}$ & Insoluble & 0 & 52 & 48 \\
\hline DMS & $12.97 \%$ & $7.85 \%$ & $\begin{array}{l}\text { Slightly } \\
\text { soluble }\end{array}$ & $\begin{array}{l}\text { Nearly fully } \\
\text { soluble } \\
\text { Forming clear } \\
\text { solution }\end{array}$ & Insoluble & 0 & 0 & 100 \\
\hline Lactose & - & - & $\begin{array}{l}\text { Freely } \\
\text { soluble }\end{array}$ & Freely soluble & Insoluble & - & - & - \\
\hline
\end{tabular}

MS is maize starch; DMS is dextrinized maize starch, solubility determined by dissolving $1 \mathrm{~g}$ in $50.0 \mathrm{ml}$ of water

TABLE 4: PHYSICAL TEST RESULTS OF FOUR TRIAL TABLET FORMULATIONS

\begin{tabular}{lcccc}
\hline Test parameter & $\begin{array}{c}\text { T1 } \\
\text { (MS+lactose) }\end{array}$ & $\begin{array}{c}\text { T2 } \\
(\text { MS+DMS) }\end{array}$ & $\begin{array}{c}\text { T3 } \\
\text { (MS+DMS+FR) }\end{array}$ & $\begin{array}{c}\text { T4 } \\
(\text { MS+DMS+FR) }\end{array}$ \\
\hline Mean Diameter $(\mathrm{mm}) \pm$ SD & $7.93 \pm 0.03$ & $7.97 \pm 0.01$ & $7.85 \pm 0.02$ & $7.83 \pm 0.03$ \\
Mean Thickness $(\mathrm{mm}) \pm$ SD & $3.95 \pm 0.05$ & $3.95 \pm 0.21$ & $3.89 \pm 0.02$ & $3.89 \pm 0.05$ \\
Weight variation $(\mathrm{mg}) \pm S D$ & $199.5 \pm 3.29$ & $200.6 \pm 1.84$ & $200.1 \pm 1.51$ & $199.9 \pm 1.51$ \\
Mean Disintegration (min) \pm SD & $0.22 \pm 0.02$ & $1.67 \pm 0.32$ & $10.15 \pm 0.07$ & $17.12 \pm 0.09$ \\
Mean Hardness $(\mathrm{kPa}) \pm$ SD & $12.96 \pm 0.49$ & $2.27 \pm 0.23$ & $4.78 \pm 1.02$ & $4.92 \pm 0.63$ \\
Mean Friability \% w/W \pm SD & $0.67 \pm 0.03$ & Fail & $0.05 \pm 0.02$ & $0.04 \pm 0.01$ \\
\hline
\end{tabular}

MS: maize starch, DMS: dextrinized maize starch, FR: furosemide. Starch binders $6.0 \% \mathrm{w} / \mathrm{w}$ and $12.0 \% \mathrm{w} / \mathrm{w}$ used in trials T1 and T2 respectively. HPC-L binders $3.2 \% \mathrm{w} / \mathrm{w}$ and $4.8 \% \mathrm{w} / \mathrm{w}$ used in trials T3 and T4, respectively 
nature of untreated MS and meet the colour reaction in iodine test.

Iodine test is a common test conducted to identify the presence of starch. Amylose in starch is responsible for the formation of a dark blue colour in the presence of iodine. Amylose linear chain forms a helix shape and iodine molecules can be bound inside this helix. The helix formation is supported by weak links between the glucose molecules. At higher temperature during dextrinization process these links break down and glucose chains uncoil, which reduce the number of iodine molecules trapped in the helix. Thus the colour intensity is reduced from dark blue to purple ${ }^{[17]}$.

DMS has good flow property compared to that of lactose. Loss on drying, $\mathrm{pH}$ and sulphated ash content values of DMS were within the ranges $<15 \%, 2.0-8.0$ and $<0.5 \%$, respectively, which are the limits specified in dextrin monograph in British Pharmacopeia (Table 2).

Initially, placebo tablets were prepared and tested for their physical properties (Table 4). In comparison to lactose-based placebo tablets (T1), the placebo tablets (T2) prepared using DMS with $12.0 \%$ w/w MS binder, failed the friability test and has considerably low hardness $(2.269 \mathrm{kPa})$. Friability is important to test the durability against crumbling of tablets during transport. Based on results of trial formulations T1 and T2, binder HPC-L was introduced in 2 concentrations to formulate furosemide tablets with DMS as the filler. Both trial tablet formulations using $3.2 \% \mathrm{w} / \mathrm{w}$ HPC-L (T3) and $4.8 \%$ w/w HPC-L (T4) as binders have acceptable hardness and friability. Furosemide tablets prepared with $4.8 \% \mathrm{w} / \mathrm{w}$ HPC-L (T4) has a disintegration time over $15 \mathrm{~min}$ and failed to comply with the specification. This could be easily overcome by incorporating a disintegrating agent in the formula. However, the tablets made under $\mathrm{T} 3$ with filler DMS and $3.2 \% \mathrm{w} / \mathrm{w}$ HPC-L binder met all physical specifications. Tablets made with DMS resulting in a better evenness in weight variation are a welcome development.

DMS as a new filler may promote low production costs compared to lactose, which is more expensive than MS. Even though DMS has good physicochemical properties, it is difficult to formulate tablets using starch binder (T2). Tablets were successfully formulated using DMS-MS and $3.2 \%$ w/w HPC-L binder, which met all the physical tests criteria. HPC-L is a stronger binder than MS therefore tablets under formula T3 were conveniently prepared.

For many decades, lactose a disaccharide was used in combination with MS as the preferred tablet fillers. MS alone cannot be used as filler because of its elastic properties. DMS-MS is a novel all polysaccharide filler combination for the tablet manufacture in pharmaceutical industry. It is therefore possible to make all polysaccharide filler tablets unaided by lactose. DMS as a tablet filler excipient carry several advantages over lactose. New filler combination is particularly useful in making tablets with active ingredients that has a potential for Maillard-reaction with lactose.

Further experiments with APIs of different strengths, properties, particularly physical properties have to be undertaken. Difficulties are likely to be encountered in the case of freely soluble APIs particularly with high strength tablets. Unlike insoluble furosemide, such ingredients tend to disturb the contribution of crystalline components in the event they dissolve and liquefy during wet granulation process. Production chain of pharmaceutical grade lactose is considerably more complex than that of MS and DMS. The chances for supply disruptions are minimal for starch unlike the early 1990's concerns regarding the presence of bovine spongiform encephalitis in the case of lactose. The outcome of the study brings the successful use of all starches filler combination DMS-MS in tablet manufacture.

\section{Acknowledgements:}

We wish to thank the academic staff and the technical staff of the Department of Pharmacy and Pharmaceutical Sciences, Faculty of Allied Health Sciences, University of Sri Jayewardenepura, Sri Lanka, for their contribution. We extend our thanks to State Pharmaceuticals Manufacturing Corporation (SPMC), Sir John Kotalawala Mawatha, Ratmalana, Sri Lanka and Asrtron Pvt Ltd, Galle Road, Ratmalana, Sri Lanka, for providing gift samples for this work.

\section{REFERENCES}

1. Nachaegari SK, Bansal AK. Coprocessed Excipients for Solid Dosage Forms. Pharm Technol 2004;28(1):52-64.

2. Gohel MC, Jogani PD, Marg BSD. A review of co-processed directly compressible excipients. J Pharm Pharm Sci 2005;8(1):76-93.

3. Patel H, Shah V, Upadhyay U. New pharmaceutical excipients in solid dosage forms - A review. Int $\mathrm{J}$ Pharm Life Sci 2011;2(8):1006-19. 
4. Kellam S. The manufacture of lactose. New Zealand Institute of Chemistry, The Dairy Industry; 1996. Available from: https://nzic.org.nz/app/uploads/2017/10/3F.pdf.

5. Vesa TH, Marteau P, Korpela R. Lactose Intolerance. J Am Coll Nutr 2013;19(2):165-75.

6. Eadala P, Waud JP, Matthews SB, Green JT, Campbell AK. Quantifying the 'hidden' lactose in drugs used for the treatment of gastrointestinal conditions. Aliment Pharmacol Ther 2009;29(6):677-87.

7. Kellar JA, Lees VW. Risk management of transmissible spongiform encephalopathies in Europe. Rev Sci Tech 2003;22(1):201-25.

8. Crowley P, Martini LG. Drug-Excipient Interactions. Pharm Technol 2001;4:7-12.

9. Wirth DD, Steven WB, Johnson RA, Steven RM, Marybeth $\mathrm{SM}$, Diana $\mathrm{KH}$, et al. Maillard Reaction of Lactose and Fluoxetine Hydrochloride, a Secondary Amine. J Pharm Sci 1998;87(1):31-9.

10. Wu Y, Levons J, Narang AS, Raghavan K, Rao VM. Reactive Impurities in Excipients: Profiling, Identification and Mitigation of Drug-Excipient Incompatibility. AAPS PharmSciTech 2011;12(4):1248-63.

11. Jivraj M, Martini LG, Thomson CM. An overview of the different excipients useful for the direct compression of tablets. Pharm Sci Technol Today 2000;3(2):58-63.
12. Swinkels JJM, Veendam. Composition and Properties of Commercial Native Starches. Starch 1985;37(1):1-5.

13. Bertoft E. Understanding Starch Structure: Recent Progress. Agronomy 2017;7(3):56.

14. Anuar MS, Briscoe BJ. The elastic relaxation of starch tablets during ejection. Powder Technol 2009;195(2):96-104.

15. Tanner T, Antikainen O, Ehlers H, Blanco D, Yliruusi J. Examining mechanical properties of various pharmaceutical excipients with the gravitation-based high-velocity compaction analysis method. Int J Pharm 2018;539(1-2):131-38.

16. Brimhall B. Structure of pyrodextrins. Ind Eng Chem 1994;36(1):72-5.

17. Tomasik P, Wiejak S, Palasinski M. The Thermal Decomposition of Carbohydrates. Part II. The Decomposition of Starch. Adv Carbohydr Chem Biochem 1989;47:279-343.

18. Laurentin A. Starch pyrodextrins: In vitro fermentation and physiological effects [dissertation]. Glasgow, Scotland; University of Glasgow; 2004.

19. Srivastava HC, Parrnar RS, Dave B. Studies on Dextrinization Part 1. Pyrodextriniration of Corn Starch in the Absence of Any Added Catalyst. Starch 1970;22(2):49-54.

20. Ueno Y, Izumi M, Kato K. Studies on Pyrodextrinization of Corn Starch. Starch 1976;28(3):77-83.

21. British Pharmacopoeia, Medicines and Healthcare Products Regulatory Agency (MHRA). London, United Kingdom: The British Pharmacopoeia Commission; 2013. 